\title{
Programa Bolsa Família e o mercado de trabalho no Paraná em 2010
}

\section{Bolsa Família Program (BPF) and the labor market of Paraná (Brazil) in 2010}

\author{
Rayssa Vieira Kruger* \\ Paulo Alexandre Nunes* \\ Deise Maria BourscheidT*
}

\begin{abstract}
The Bolsa Familia Program (BPF) started in 2003, has been criticized mainly because of the conditions imposed for the receipt of the benefit and due to their enforcement. Thus, this study aims to examine whether there is a relationship between the proportion of families participating in the Bolsa Familia Program and the labor market in Parana, through the bivariate Moran's I statistic. The results showed that activities related to the urban sector have greater sensitivity to the BFP and that the South Center Paraná has a disadvantaged labor market.
\end{abstract}

Keywords: Bolsa Família, employment, economic performance.

\section{Resumo}

O Programa Bolsa Família, iniciado em 2003, tem sofrido críticas devido, especialmente, às condicionalidades impostas para o recebimento da transferência, bem como a fiscalização do cumprimento das mesmas. Assim, este estudo tem como objetivo analisar se existe relação entre proporção de famílias beneficiárias do Programa Bolsa Família e o mercado de trabalho no Paraná, por meio da estatística I de Moran bivariado. Os resultados mostraram que atividades ligadas ao setor urbano possuem maior sensibilidade ao programa Bolsa Família e que o Centro Sul paranaense possui um mercado de trabalho desfavorecido.

Palavras-chaves: Bolsa Família, emprego, desempenho econômico.

*Universidade Federal da Fronteira Sul, correos-e: krugerrayssa@gmail.com, paulo.nunes@ uffs.edu.br, deise.bourscheidt@uffs.edu.br 


\section{Introdução}

Desde o passado, a pobreza está presente na sociedade, e em cada período histórico ela apresenta diferentes características, considerando os graus de desenvolvimento econômico, político e social. Mesmo com o aumento da geraçáo de riqueza que o capitalismo proporcionou, náo se pode constatar o término da pobreza e sim a retroalimentação das desigualdades econômicas e sociais (Curralelo, 2012). Para Curralelo (2012), o contexto mais recente da economia brasileira é caracterizado pelo crescimento econômico a partir da segunda metade da década de 2000, tendo em vista a expansão do mercado consumidor interno, a expansão do emprego, a inclusáo social e o enfrentamento da pobreza. Fatores que estáo correlacionados e portanto adquiriram espaço na estratégia de desenvolvimento no país.

Pode-se citar como uma dessas estratégias a inserção de políticas públicas na sociedade. Segundo Ávila (2013), toda política pública depois de pensada e implantada, causa resultados e impactos positivos e negativos, dependendo da região, das instituiçóes e dos atores envolvidos no processo.

Nessa percepção, inicia-se no ano de 2003, o Programa Bolsa Família (PBF), criado pelo governo federal através da junçáo de programas pré-existentes, sendo os principais segundo Licio et al. (2011), Bolsa Escola, Bolsa Alimentação, Auxílio-Gás, Cartão Alimentação, além do Cadastro Único. Desse modo, o objetivo geral do programa é de diminuir a pobreza e a fome no país.

O programa em questão é de transferência de renda condicionada, classificação que segundo Soares e Sátyro (2009) exigem contrapartida dos beneficiários, ou seja, é necessário que eles executem açóes para o próprio benefício e de suas famílias. No caso do Bolsa Família, as condicionalidades impostas são a frequência escolar das crianças, a vacinação obrigatória em dia e a comprovação de baixa renda.

No que se refere a renda os autores ainda colocam que é esperado que os agentes municipais do PBF atualizem os cadastros das famílias a cada dois anos, pois um aumento na renda per capita, seja ele por um emprego formal, pode exceder o valor máximo de renda para ser beneficiado pelo programa e consequentemente ser excluído do mesmo.

Além disso, há muitas críticas em relação ao "efeito-preguiça", o qual postula que, ao condicionar um benefício à renda da família, os beneficiários podem se acomodar e diminuir a oferta de trabalho. Em outras palavras, haveria um desincentivo ao trabalho, principalmente nas famílias que recebem o benefício básico, fornecido para famílias extremamente pobres (Soares e Sátyro, 2009). 


\section{Quadro 1 \\ Tipos de benefícios do PBF}

Benefício básico: $\mathrm{R} \$ 85.00$

Benefício variável de 0 a 15 anos: $\mathrm{R} \$ 39.00$

Benefício variável à gestante: $\mathrm{R} \$ 39.00$

Benefício variável nutriz: $\mathrm{R} \$ 39.00$

Benefício variável vinculado ao adolescente: $\mathrm{R} \$ 46.00$

Benefício para superação da extrema pobreza: calculado caso a caso
Concedido apenas para famílias extremamente pobres (renda mensal por pessoa de até $\mathrm{R} \$ 85.00$ ).

Concedido às famílias com crianças ou adolescentes de 0 a 15 anos de idade.

Concedido às famílias que tenham gestantes em sua composição.

Pagamento de nove parcelas consecutivas, a contar da data do início do pagamento do benefício, desde que a gestação tenha sido identificada até o nono mês.

A identificação da gravidez é realizada no Sistema Bolsa Família na Saúde. O Cadastro Único não permite identificar as gestantes.

Concedido às famílias que tenham crianças com idade entre 0 e 6 meses em sua composição.

Pagamento de seis parcelas mensais consecutivas, a contar da data do início do pagamento do benefício, desde que a criança tenha sido identificada no $\mathrm{Ca}$ dastro Único até o sexto mês de vida.

Concedido a famílias que tenham adolescentes entre 16 e 17 anos, limitado a dois benefícios por família.

Transferido às famílias do Programa Bolsa Família que continuam em situação de extrema pobreza (renda mensal por pessoa de até R \$77), mesmo após o recebimento dos outros benefícios. Ele é calculado para garantir que as famílias ultrapassem o limite de renda da extrema pobreza.

Fonte: elaboraçáo dos autores, com base nos dados do Ministério do Desenvolvimento Social e Combate à Fome, MDS (2017).

Os benefícios transferidos as famílias são repassados de acordo com o perfil da família registrada no Cadastro Único, como mostra o quadro 1:

Com base nisso, esse estudo teve por objetivo responder se existe relação entre a proporção de famílias beneficiadas com o programa Bolsa Família e o mercado de trabalho em 2010. O estudo privou-se apenas ao estado do Paraná, contribuindo para a análise de um cenário mais específico do programa em questão. 
As próximas sessōes deste trabalho serão apresentadas a revisão de literatura, a metodologia utilizada, resultados alcançados e as consideraçóes finais respectivamente.

\section{Revisáo de literatura}

O PBF é amplo, observando a população beneficiada que alcançou um quarto da populaçáo no ano de 2009. Contudo, ao analisar o Programa segundo a mobilização de recursos, é razoável, sendo que em 2009 o PBF representava $0.7 \%$ da renda total das famílias e $0.4 \%$ do PIB (De castro e Modesto, 2010). Dados mais atualizados mostram que, em fevereiro de 2015, o PBF beneficiou 14014252 famílias, as quais receberam benefícios com valor médio de R \$ 167.62, segundo o Ministério do Desenvolvimento Social (MDS, 2015). Os programas focalizados nos mais pobres existem desde a década de setenta, mas nesta época o público alvo era limitado, tendo assim pouca visibilidade (Rocha, 2011).

Atualmente as regiôes brasileiras apresentam características distintas em relação ao número de beneficiários. Segundo Marques et al. (2007), quando se compara as regiōes, observa-se que há grande desigualdade entre elas, principalmente entre a região nordeste e o Sul, tendo a primeira, com o maior número de beneficiários.

Em termos de transferência de renda, redução da pobreza e melhoria do bem-estar social, Pinto (2012) aponta resultados positivos, que colocam o PBF como um prestígio nacional e internacional, tendo em vista que seus efeitos são observados em regióes que ainda não possuem um mercado de trabalho dinâmico e inclusivo. $\mathrm{O}$ autor ainda explana que a promoção de oportunidades de geração de renda, qualificação profissional, estímulo ao empreendedorismo e acesso ao crédito popular também fazem parte do objetivo do programa, sendo alcançado por meio da inclusão dos beneficiários em programas como ProJovem, Pronaf, Brasil Alfabetizado, Economia Solidária, Microcrédito do BNB, Luz para todos, PLANSEQ, além da inserção dos beneficiários no sistema financeiro.

Lazani (2011) também aborda a importância que o PBF adquiriu na discussão política nacional. Mas destaca que há uma contradição em uma suavizaçáo da pobreza extrema e ao mesmo tempo não há uma grande chance de uma transformação material mais profunda nas relações sociais, o que leva a perceber que o programa náo pode ser visto apenas como assistencialista, pois ainda existem questóes sociais a serem analisadas. Náo se pode deixar de citar, que o autor coloca que em regióes isoladas do país, o acesso ao programa foi a primeira chance dos cidadáos terem sua primeira renda regular. 
Em relação a movimentação do mercado de trabalho, os beneficiados do PBF possuem características específicas, principalmente para as mulheres. Segundo o estudo de Suárez e Libardoni (2007), as beneficiárias obtém o benefício como a única proteção certa para a família, já que o trabalho informal é incerto e instável. Assim, elas preferem cuidar dos filhos e da casa do que trabalharem fora. Mas não é apenas na movimentação do emprego que as mulheres se diferenciam, os autores ainda colocam que por elas terem acesso a um cartâo e receberem uma renda mensal fixa, há um aumento no poder de compra, mesmo que o mercado ainda seja restrito.

Considerando o mercado de trabalho tanto feminino como masculino, os benefícios do PBF são direcionados a famílias com filhos, e umas das condicionalidades do programa é a frequência escolar. Um ponto a mais que se destaca segundo Parker e Skoufias (2000 em Oliveira et al. 2007), no caso das mulheres, para cumprir as contrapartidas impostas pelo programa, há um maior consumo de tempo, o que faz com que reduza o tempo para se dedicar ao trabalho ou há uma redução no tempo dedicado ao lazer.

Discutindo-se a questão do emprego, há um fator relevante para o mercado de trabalho dos beneficiários que é a escolaridade. Segundo o De Castro y Modesto (2010), a insuficiente inserção deles no mundo do trabalho é devida ao baixo nível de escolaridade. No período de 2003 a 2010, $52.7 \%$ dos beneficiários ocupados, com idade entre 16 e 65 anos, tinham no máximo quatro anos de estudo e $18.4 \%$ deles não tinha nenhum ano de estudo. No entanto, o emprego é acompanhado por diferentes situaçóes, uma no meio rural e outra no meio urbano. As famílias beneficiárias urbanas tendem a mudar do trabalho formal para o informal, ou seja, deixa-se o emprego seguro e com melhor benefício. Mesmo não reduzindo toda a força de trabalho, as famílias podem se tornar mais vulneráveis, com o fato de não receberem o benefício do programa. Porém, um outro cenário é observado no meio rural. Com o incentivo as mulheres beneficiárias rurais a abandonarem a força de trabalho, elas se tornam menos autossuficientes. Ao contrário dos homens beneficiários rurais que aumentam suas horas de trabalho, fazendo com que as horas de trabalho doméstico não sejam afetadas, mas sim, a autonomia das mulheres rurais, como mostra os estudo de Brauw et al. (2013).

\section{Metodologia}

A metodologia utilizada para este estudo divide-se em duas partes, sendo que na primeira parte é feito um estudo sobre a análise de correlação entre a variável de Famílias beneficiadas pelo Programa Bolsa Família 
(PBF) nos municípios paranaenses em 2010, com as variáveis referentes ao mercado de trabalho nos municípios paranaenses no ano de 2010, e a segunda parte da metodologia refere-se à Análise Exploratória de Dados Espaciais.

\subsection{Análise de Correlação}

A análise de correlação é uma estatística bivariada, e com o uso dela, tem-se como principal objetivo verificar se há relação entre duas variáveis, e se esta relação é forte, fraca ou nula. Esta relação será medida pelo coeficiente de correlação de Pearson, conforme a equação 1:

$$
r=\frac{\sum_{i=1}^{n}\left(X_{i}-\bar{X}\right)\left(Y_{i}-\bar{Y}\right)}{\sqrt{\sum_{i-1}^{n}\left(X_{i}-\bar{X}\right)^{2}\left(Y_{i}-\bar{Y}\right)^{2}}}
$$

Sendo $\mathrm{X}$ e $\mathrm{Y}$ as variáveis a serem analisadas. $\mathrm{O}$ total de observaçóes para cada variável é de 399, o número total de municípios do Estado do Paraná. O coeficiente de correlação não é um̄a estatística de causalidade, pois a mesma não tem como objetivo a análise do tipo causa-efeito, a mesma apenas apresenta a relação que pode haver entre as variáveis, desta forma, não se faz distinção entre variáveis dependente e independente.

O coeficiente de correlação pode possuir valores dentro da faixa de -1 $\mathrm{a}+1$, sendo -1 representando a perfeita correlação negativa entre as variáveis, e +1 a perfeita correlaçáo positiva entre as variáveis. Nesta faixa de valores, o número 0 representa a não-correlação entre as variáveis, ou melhor, não há relação entre as mesmas.

O coeficiente de correlação também é uma estatística, isto é, não se deve apenas observar os seus valores e decidir se há correlação ou não entre as variáveis, assim, como toda estatística, é necessário testar seu resultado por meio da inferência estatística, e a inferência mais usual para tal é o teste de hipóteses.

O coeficiente de correlação, conforme a equação 1 , é representado pela letra r, porém, é uma estimativa da correlação populacional $\rho$, logo, r é uma medida amostral, com base nesta estimativa pode-se obter informaçōes e inferir sobre o comportamento populacional. Assim, a hipótese a ser formulada e testada é a seguinte:

H0: A Correlação populacional é igual a zero $(\rho=0)$.

Ha: A correlação populacional é diferente de zero $(\rho \neq 0)$.

Esta estatística segue a distribuiçáo t de Student, com graus de liberdade $n-2$. A equação para o teste de hipótese, está expressa na equação 2, conforme Hoffmann (2006) é: 


$$
t=\frac{r \sqrt{n-2}}{\sqrt{1-\mathrm{r}^{2}}}
$$

O resultado obtido pela equaçáo 2 , deve ser comparado com o valor crítico tabelado da distribuição t de Student, considerando o nível de significância e os graus de liberdade. $\mathrm{O}$ nível de significância representa o que na teoria estatística é extremamente importante para as análises de inferência estatística, o Erro Tipo 1, conforme Hoffmann (2006) é a situação na qual $\mathrm{H} 0$ é rejeitado, dado que $\mathrm{H} 0$ é verdadeira. $\mathrm{O}$ Erro Tipo 1 é representado pelo símbolo $\alpha$. Para os propósitos deste estudo, o cálculo da estimativa do coeficiente de correlação e o teste de hipótese, fez uso do software R Core Team (2015). Com o uso do software não é necessário fixar um valor para o $\alpha$, pois o mesmo fornece uma estimativa, conhecido como p-valor, e quanto mais próximo de 0 for esta estimativa, pode-se considerar que o coeficiente de correlação é estatisticamente significante, isto é, pode-se rejeitar $\mathrm{H} 0$.

A aplicação da análise de correlação é importante para poder visualizar a relação da Proporção de Famílias Beneficiadas pelo Programa Bolsa Família (PBF) com as demais variáveis que estão descritas no quadro 2. Aquelas que obtiverem correlação significativa serão selecionadas para a próxima etapa da metodologia, que está descrita no tópico a seguir.

\subsection{Análise exploratória de dados espaciais}

A segunda parte da metodologia aplicada para este estudo é conhecido na literatura como Análise Exploratória de Dados Espaciais (AEDE), mais precisamente, a estatística I de Moran bivariado. Conforme Almeida (2004: 8) "A ideia intuitiva é descobrir se os valores de uma variável observada numa dada região guarda uma relação sistemática com os valores de uma outra variável observada em regiōes vizinhas". O método para a estimativa da estatística I de Moran é dada pela equação 3.:

$$
I_{k l}=\frac{Z_{k}^{\prime} W z_{\mathrm{j}}}{n}
$$

Sendo $z_{k}$ e $z_{l}$ as variáveis analisadas padronizadas, $W$ é a matriz de pesos espaciais, para este estudo foi utilizada a matriz de pesos espaciais Rainha, o nome da matriz de peso espacial Rainha, é uma referência ao movimento desta peça em um jogo de xadrez, que além das fronteiras entre os municípios, também se considera os vértices. No denominado tem-se a variável n, isto é, o número de unidades espaciais, neste caso, o número de municípios do Estado do Paraná. 
A estatística I de Moran é um coeficiente de associação linear, e seu valor esperado é -[1/(n-1)], neste estudo é- $[1 /(399-1)]=-0,0025$, este valor representa a não autocorrelação espacial entre as variáveis, e segue a distribuição de probabilidade Normal Padrão, pois a medida que o número de unidades espaciais aumenta, sua média (esperança) tende a zero, e variância igual a 1 . Seus valores limites, como o coeficiente de correlação já conhecido é $-1 \mathrm{e}+1$, isto é, quanto mais próximo de -1 a autocorrelação espacial é negativa, indicando que, quando as unidades espaciais obtiverem $z_{k}$ elevados, são circuncidadas por unidades espaciais com $\mathrm{z}_{1}$ baixos. E quando $\mathrm{Ik}_{1}$ estiver próximo de +1 representa autocorrelação positiva, sendo unidades espaciais com $\mathrm{z}_{\mathrm{k}}$ elevados circuncidadas por unidades espaciais com $\mathrm{z}_{1}$ também elevados.

Assim, os resultados desta estatística serão representados por uma tabela contendo o valor estimado do I de Moran bivariado, desvio-padrão e o p-valor, e também por mapas de dispersão de Moran, para o cálculo desta estatística será utilizado o software GeoDa (Anselin et al., 2006). Tal estatística será feita apenas com as variáveis que se mostraram correlacionadas negativamente ou positivamente com a variável proporção de famílias beneficiadas como Programa Bolsa Família no ano 2010, as demais serão excluídas das análises.

\subsection{Dados da pesquisa}

O objetivo deste estudo é fazer uma análise da relação entre proporção de famílias beneficiárias do Programa Bolsa Família e o mercado de trabalho municipal, tendo como variáveis referentes ao desempenho municipal o PIB per capita municipal e as taxas de desemprego total, por zonas (urbana e rural), por gênero, taxa de emprego atividade econômica, e por escolaridade. Segue abaixo o quadro $2 \mathrm{com}$ a descrição das variáveis utilizadas para este estudo.

O número de famílias beneficiadas pelo PBF por município foi coletado na base de dados do Ministério do Desenvolvimento Social e Combate à Fome, Data Social (MDS, 2015). Para transformar esse dado em taxa, foi feito a razão entre essa variável sobre o número de domicílios particulares por município, o número de domicílios foi utilizado como uma proxy do número de famílias por município. A taxa de desemprego total por município foi estimada com base na estimativa de Ipardes (2004: 58), a fórmula (4) apresenta o método para tal estimativa.

$$
\operatorname{TXDEST}_{i}=\left(1-\frac{P O T_{i}}{P E A T_{i}}\right) * 100
$$




\section{Quadro 2}

Descrição das variáveis utilizadas nesta pesquisa, todas referentes ao ano de $\mathbf{2 0 1 0}$

\begin{tabular}{ll}
\hline \multicolumn{1}{c}{ Variáveis } & \multicolumn{1}{c}{ Descrição } \\
\hline TXFRPBF10 & Proporção de famílias que recebem o Programa Bolsa Família - \% \\
TXDEST10 & Taxa de desemprego total - \% \\
TXDESU10 & Taxa de desemprego urbano - \% \\
TXDESR10 & Taxa de desemprego rural - \% \\
TXEMPAG10 & Taxa de emprego na agropecuária - \% \\
TXEMPIT10 & Taxa de emprego na indústria de transformação - \% \\
TXEMPC10 & Taxa de emprego no comércio - \% \\
TXEMPS10 & Taxa de emprego nos serviços - \% \\
TXEMPAP10 & Taxa de emprego na administração pública - \% \\
TXEMPM10 & Taxa de emprego masculino - \% \\
TXEMPF10 & Taxa de emprego feminino - \% \\
TXEFS10 & Taxa do saldo de emprego formal total - \% \\
TXEFMS10 & Taxa do saldo de emprego formal masculino - \% \\
TXEFFS10 & Taxa do saldo de emprego formal feminino - \% \\
TXEMPAN10 & Taxa de emprego de pessoas analfabetas - \% \\
TXEMPEF10 & Taxa de emprego de pessoas com ensino fundamental completo - \% \\
TXEMPEM10 & Taxa de emprego de pessoas com ensino médio completo - \% \\
TXEMPSUP10 & Taxa de emprego de pessoas com ensino superior completo - \% \\
PIBPC10 & PIB per capita em R $\$ 1.000,00$ \\
\hline
\end{tabular}

Fonte: elaborado pelos autores com base nos dados do Ipardes (2015) e MDS (2015).

Sendo POTi a população ocupada total no município $i$, e PEATi a população economicamente ativa no município $i$. Os dados sobre a população ocupada por município e a populaçáo economicamente ativa por município para o ano de 2010 foram coletados na Base de Dados do Estado do Paraná do Instituto Paranaense de Desenvolvimento Econômico e Social - Ipardes (2015).

A estimativa da taxa de desemprego para as áreas urbanas e rurais dos municípios paranaenses foram realizadas do mesmo modo que a apresentada na equação 4, porém, com dados referentes à zona urbana e rural. Os dados sobre a população ocupada e populaçáo economicamente ativa também foram coletadas na Base de Dados do Estado do Paraná. A equaçáo (5) apresenta o modo da estimativa das taxas de desemprego urbana e rural. 


$$
\operatorname{TXDEST}_{i}=\left(1-\frac{P O_{i}^{j}}{P E A_{i}^{j}}\right) * 100
$$

O sobrescrito $j$ representa se as variáveis são referentes à área urbana ou rural dos municípios paranaenses.

A taxa de emprego por atividade (agropecuária, indústria de transformação, comércio, serviços e administraçáo pública) foram calculadas pela razáo entre a população ocupada (PO) por atividade pela população economicamente ativa (PEA) por município.

Taxas de emprego por gênero (masculino e feminino) também foram estimadas do mesmo modo que a taxa de emprego por atividade, porém, os dados referem-se ao universo masculino ou feminino. Da mesma forma, as taxas de emprego por escolaridade, sendo subdivididas em analfabetas, ensino fundamental completo, ensino médio completo e ensino superior completo.

Assim, para as estimativas das taxas de desemprego (total, e por áreas), taxa de emprego (por atividade, gênero e escolaridade) foram utilizados dados coletados na Base de Dados do Estado do Paraná - Ipardes (2015), e estão em relação à PEA total.

Após esta descrição das metodologias aplicadas e das variáveis utilizadas, o próximo tópico irá apresentar os resultados obtidos com esta pesquisa.

\section{Resultados}

Este tópico está divido em três subtópicos, sendo que o primeiro apresenta a estatística descritiva das variáveis utilizadas para esta pesquisa, o segundo apresenta o resultado da análise de correlação entre as variáveis, e o terceiro irá apresentar os resultados referentes ao I de Moran bivariado.

\subsection{Estatística descritiva}

O primeiro passo a ser feito ao trabalhar com variáveis é ter informações básicas sobre as mesmas, como o valor mínimo e máximo, a média, desvio padrão e coeficiente de variação. $\mathrm{O}$ quadro 3 apresenta os valores das principais medidas de posição e dispersão das variáveis utilizadas nesta pesquisa.

Como todas as variáveis referem-se aos municípios paranaenses, então, o número total de observaçóes de cada variável é de 399. Das medidas apresentadas neste quadro, a que mais chama atenção é o Coeficiente de Variaçáo, pois a mesma informa o grau de concentração em torno da 


\section{Quadro 3}

Medidas de posiçáo e dispersão das variáveis utilizadas na pesquisa

\begin{tabular}{|c|c|c|c|c|c|c|}
\hline Variáveis & $\begin{array}{l}\text { Número de } \\
\text { observaçōes }\end{array}$ & $\begin{array}{c}\text { Valor } \\
\text { mínimo }\end{array}$ & $\begin{array}{c}\text { Valor } \\
\text { máximo }\end{array}$ & Média & $\begin{array}{l}\text { Desvio } \\
\text { padrão }\end{array}$ & $\begin{array}{l}\text { Coeficiente } \\
\text { de variação }\end{array}$ \\
\hline TXFRPBF10 & 399 & 3.76 & 43.53 & 17.42 & 7.43 & 42.65 \\
\hline TXDEST10 & 399 & 0.00 & 11.22 & 4.59 & 1.82 & 39.65 \\
\hline TXDESU10 & 399 & 0.00 & 12.85 & 5.70 & 1.99 & 34.85 \\
\hline TXDESR 10 & 399 & 0.00 & 24.06 & 2.48 & 2.18 & 87.92 \\
\hline $\begin{array}{l}\text { TXEM- } \\
\text { PAG10 }\end{array}$ & 399 & 0.03 & 71.94 & 3.80 & 5.71 & 150.27 \\
\hline TXEMPIT10 & 399 & 0.00 & 69.97 & 9.83 & 11.29 & 114.79 \\
\hline TXEMPC10 & 399 & 0.00 & 24.92 & 6.05 & 3.63 & 59.90 \\
\hline TXEMPS10 & 399 & 5.76 & 55.95 & 12.97 & 5.39 & 41.51 \\
\hline TXEMPAP10 & 399 & 2.69 & 30.88 & 8.08 & 3.51 & 43.41 \\
\hline TXEMPM10 & 399 & 4.34 & 77.48 & 19.65 & 11.32 & 57.58 \\
\hline TXEMPF 10 & 399 & 4.32 & 43.07 & 13.83 & 5.92 & 42.81 \\
\hline TXEFS10 & 399 & -18.66 & 16.00 & 1.21 & 2.83 & 234.36 \\
\hline TXEFMS10 & 399 & -30.22 & 20.62 & 1.03 & 3.61 & 350.63 \\
\hline TXEFFS 10 & 399 & -15.40 & 14.60 & 1.46 & 2.46 & 168.55 \\
\hline $\begin{array}{l}\text { TXEM- } \\
\text { PAN10 }\end{array}$ & 399 & 0.00 & 2.84 & 0.19 & 0.23 & 122.67 \\
\hline TXEMPEF 10 & 399 & 0.53 & 23.17 & 4.46 & 2.74 & 61.53 \\
\hline $\begin{array}{l}\text { TXEM- } \\
\text { PEM10 }\end{array}$ & 399 & 2.17 & 36.59 & 11.81 & 5.94 & 50.31 \\
\hline $\begin{array}{l}\text { TXEMP- } \\
\text { SUP10 }\end{array}$ & 399 & 0.41 & 22.14 & 3.75 & 1.88 & 50.00 \\
\hline 1PIBPC10 $0^{21}$ & 399 & 3.04 & 55.54 & 7.75 & 4.46 & 57.49 \\
\hline
\end{tabular}

Fonte: elaborado pelos autores com base nos dados do Ipardes (2015) e MDS (2015).

média de cada variável. Sendo que o método de análise desta medida de dispersão é:

Alta concentração: $\mathrm{CV}<15 \%$

Média concentração: $15 \%<\mathrm{CV}<30 \%$

Baixa concentração: $\mathrm{CV}>30 \%$.

Assim, com base nos resultados apresentados, tem-se que todas as variáveis possuem baixa concentração em torno da média, indicando que seus valores são altamente dispersos, alguns próximos a situação de Média concentração, e outros valores bem alto, indicando assim, a presença de 
valores discrepantes na série estatística de tais variáveis, como o caso de TXEFMS10 $(\mathrm{CV}=351 \%)$, TXEFS $10(\mathrm{CV}=234 \%)$, TXEMPAG10 $(\mathrm{CV}$ $=150 \%)$, TXEMPAN10 $(\mathrm{CV}=123 \%)$ e TXEMPIT10 $(\mathrm{CV}=115 \%)$. As demais variáveis possuem coeficiente de variação inferior à 100\%, e conforme o método de análise, ainda possuem alta dispersão em torno da média. A variável TXFRPBF10, mesmo o coeficiente de variaçấo indicar que há baixa concentração em torno da média, o seu valor foi um dos menores em relação às outras variáveis analisadas. $\mathrm{O}$ próximo tópico irá explorar melhor a distribuição dos valores de tais variáveis nos municípios paranaenses, procurando identificar quais municípios possuem os valores discrepantes.

\subsection{Correlaçâo das variáveis}

Este tópico tem como objetivo analisar se há relação linear da variável de famílias beneficiárias do PBF e o mercado de trabalho nos municípios paranaenses em 2010 com as demais variáveis sobre o desempenho econômico dos municípios paranaenses, referentes ao mercado de trabalho e o PIB per capita. Aquelas variáveis que apresentarem relaçóes significativas serão enfatizadas no próximo tópico, que tem como objetivo fazer uma análise exploratória de dados espacial bivariada. O quadro 4 apresenta os valores do coeficiente de correlação e os respectivos p-valor, necessário para decisão de significância estatística.

Das 18 variáveis analisadas, apenas cinco não foram estatisticamente significativas ao nível de 5\%. Quando se considera nível de significância de $10 \%$, esse número cai para apenas dois variáveis, sendo elas a Taxa de Desemprego Rural e Taxa de Emprego na Agropecuária, com base no coeficiente de correlação para estas variáveis em relação à proporção de famílias beneficiadas pelo Programa Bolsa Família, não há relação linear entre as mesmas.

Atividades ligadas ao setor urbano possuem forte relação linear com a proporção de famílias beneficiadas pelo $\mathrm{PBF}$, conforme pode ser observado no quadro 4 com o coeficiente de correlação desta variável com Taxa de desemprego urbano (correlação positiva); Taxa de emprego na indústria de transformação, no comércio e nos serviços (correlação negativa). A taxa de emprego na administração pública, mesmo sendo significativo ao nível de $10 \%$, o coeficiente de correlação, em valor absoluto, é baixo, em torno de 0.09 .

Quando se analisa a proporção de famílias beneficiadas pelo PBF em relação à gênero, movimentaçóes no mercado de trabalho para pessoas do sexo masculino e feminino são altamente significativos, porém, o maior peso se concentra na movimentação no mercado de trabalho para pessoas 


\section{Quadro 4}

\section{Coeficiente de correlaçáo entre a proporçáo de famílias beneficiadas pelo PBF em 2010 e variáveis selecionadas referentes ao ano de 2010}

\begin{tabular}{lll}
\hline \multicolumn{1}{c}{ Variáveis } & $\begin{array}{c}\text { Proporção de famílias beneficiadas } \\
\text { pelo PBF - 2010 }\end{array}$ \\
\cline { 2 - 3 } & $\begin{array}{c}\text { Coeficiente de } \\
\text { Correlaçáo }\end{array}$ & p-valor \\
\hline Taxa de desemprego total - \% & -0.0957 & 0.0562 \\
Taxa de desemprego urbano - \% & 0.2653 & 0.0000 \\
Taxa de desemprego rural - \% & -0.0751 & 0.1342 \\
Taxa de emprego na agropecuária - \% & -0.0288 & 0.5662 \\
Taxa de emprego na indústria de transformaçáo - \% & -0.4141 & 0.0000 \\
Taxa de emprego no comércio - \% & -0.4069 & 0.0000 \\
Taxa de emprego nos serviços - \% & -0.3099 & 0.0000 \\
Taxa de emprego na administração pública - \% & 0.0877 & 0.0800 \\
Taxa de emprego masculino - \% & -0.4213 & 0.0000 \\
Taxa de emprego feminino - \% & -0.5972 & 0.0000 \\
Taxa do saldo de emprego formal total - \% & -0.1798 & 0.0003 \\
Taxa do saldo de emprego formal masculino - \% & -0.1105 & 0.0273 \\
Taxa do saldo de emprego formal feminino - \% & -0.2654 & 0.0000 \\
Taxa de emprego de pessoas analfabetas - \% & -0.0922 & 0.0658 \\
Taxa de emprego de pessoas com ensino fundamen- & -0.3411 & 0.0000 \\
tal completo - \% & & \\
Taxa de emprego de pessoas com ensino médio \\
completo - \%
\end{tabular}

Fonte: elaborado pelos autores com base nos dados do Ipardes (2015) e MDS (2015).

do sexo feminino, os motivos para tal situação já foram apresentados no referencial teórico.

Com base no mercado de trabalho das pessoas com diferentes graus de instruçáa, observa-se que a taxa de emprego de pessoas com ensino fundamental completo, ensino médio completo e ensino superior completo, foram estatisticamente significativos ao nível de 5\%, a taxa de emprego de pessoas analfabetas podem ser consideradas significativas ao nível de $10 \%$, a correlação observada para tais variáveis em relação à proporção de famílias beneficiadas pelo PBF foram negativas, isto é, va- 
riaçóes na taxa de emprego de pessoas com os graus de instrução apresentados são acompanhadas por variaçáo no sentido inverso da proporçáo de famílias beneficiadas, não sendo o caso de causação, mas sim apenas a associação linear entre as variáveis. Destas variáveis, a taxa de emprego de pessoas com ensino médio completo é a que obtém o coeficiente de correlação em valor absoluto.

Por fim, quando se analisa a associação linear entre as variáveis, proporção de famílias beneficiadas pelo PBF e o PIB per capita municipal, o coeficiente apresentou significância estatística ao nível de 5\%, havendo assim correlação negativa, isto é, municípios que possuem PI0B per capita elevado são acompanhados por baixa proporção de famílias beneficiadas pelo PBF. Uma explicação para isso pode ser que nos municípios ou regióes que possuem PIB per capita alto pode haver maior geração de emprego e riquezas, havendo assim maiores oportunidades para a população de baixa renda.

\subsection{Autocorrelação espacial}

Neste tópico será analisada a autocorrelação espacial, por meio da estatística I de Moran bivariado, da variável proporção de famílias beneficiadas com o PBF e as demais variáveis que obtiveram coeficiente de correlação significativo ao nível de 5\% de confiança.

Assim, as variáveis que se mostraram significantes ao nível de $5 \% \mathrm{com}$ o coeficiente de correlaçáo foram: Taxa de Desemprego Urbano, Taxa de Emprego na Indústria de Transformação, Taxa de Emprego no Comércio, Taxa de Emprego nos Serviços, Taxa de Emprego Masculino, Taxa de Emprego Feminino, Taxa do Saldo de Emprego Formal, Taxa do Saldo de Emprego Formal Masculino, Taxa do Saldo de Emprego Formal Feminino, Taxa de Emprego de Pessoas com Ensino Fundamental Completo, Taxa de Emprego de Pessoas com Ensino Médio Completo, Taxa de Emprego de Pessoas com Ensino Médio Completo e PIB per capita. A sequência da apresentação destes resultados seguirá a forma que está descrita neste parágrafo. O Quadro 5 mostra os resultados da Estatística I de Moran bivariado.

Observa-se no mapa 1 que o Centro Sul é a regiáo que possui a maior aglomeraçáo de municípios com padrão alto-alto. À vista disso, interpreta-se que nesse agrupamento de municípios há uma maior associação entre proporção de famílias beneficiadas pelo PBF e a taxa de desemprego urbano. Dentre os municípios que se destacam são: Arapuã, o qual tem a maior taxa de desemprego urbano no Paraná (12.85\%) e também observa-se nesse agrupamento o município de Laranjal, com a maior taxa de proporção de famílias beneficiadas (43.53\%) em 2010, como mostra 


\section{Quadro 5}

Estatística I de Moran bivariado das variáveis selecionadas e o respectivo nível de significância

\begin{tabular}{lcc}
\hline \multicolumn{1}{c}{ Variáveis } & $\begin{array}{c}\text { Proporção de famílias beneficiadas } \\
\text { pelo PBF-2010 }\end{array}$ \\
\cline { 2 - 3 } & I de Moran & p-valor \\
\hline Taxa de desemprego urbano - \% & 0.1985 & 0.0010 \\
Taxa de emprego na indústria de transformaçáo & -0.2269 & 0.0010 \\
- \% & & \\
Taxa de emprego no comércio - \% & -0.1014 & 0.0010 \\
Taxa de emprego nos serviços - \% & -0.1199 & 0.0010 \\
Taxa de emprego masculino - \% & -0.1918 & 0.0010 \\
Taxa de emprego feminino - \% & -0.3010 & 0.0010 \\
Taxa do saldo de emprego formal total - \% & -0.0377 & 0.0620 \\
Taxa do saldo de emprego formal masculino - \% & 0.0073 & 0.3940 \\
Taxa do saldo de emprego formal feminino - \% & -0.1195 & 0.0010 \\
$\begin{array}{l}\text { Taxa de emprego de pessoas com ensino funda- } \\
\text { mental completo - \% }\end{array}$ & -0.1353 & 0.0010 \\
Taxa de emprego de pessoas com ensino médio & -0.2613 & 0.0010 \\
completo - \% & & \\
Taxa de emprego de pessoas com ensino superior & -0.2345 & 0.0010 \\
completo - \% & & 0.0010 \\
PIB per capita em R\$ 1.000,00 & -0.1269 & \\
\hline
\end{tabular}

Fonte: elaborado pelos autores com base nos dados do Ipardes (2015) e MDS (2015).

o quadro 3 da sessão 3.1. Ou seja, a regiáo Centro Sul Paranaense possui municípios que atendem os quesitos para recebimento dos auxílios do PBF, apresentando um mercado de trabalho desfavorecido.

Nas regióes Noroeste, Norte Central e Oeste ocorreu a existência de clusters do tipo baixo-baixo, o que significa que os municípios que forma esse agrupamento, como também seus vizinhos, apresentam valores baixos em relação as variáveis analisadas. Um exemplo dessa situação é o município de Quatro Pontes, localizado no Oeste do Paraná, com a menor taxa de proporção de famílias beneficiadas (3.76\%) e com uma taxa de desemprego urbano de $1.98 \%$.

Como o coeficiente de correlação das variáreis abordadas no quadro 4 é negativo, uma menor taxa de emprego na Indústria de Transformação nos municípios paranaenses, maior será a taxa de proporção de famílias beneficiadas pelo PBF e vice versa. Logo, quando analisa-se a autocorre- 


\section{Mapa 1 \\ Mapa de clusters bivariado para proporçáo de famílias beneficiadas pelo PBF e Taxa de Desemprego Urbano nos municípios \\ paranaenses, 2010}

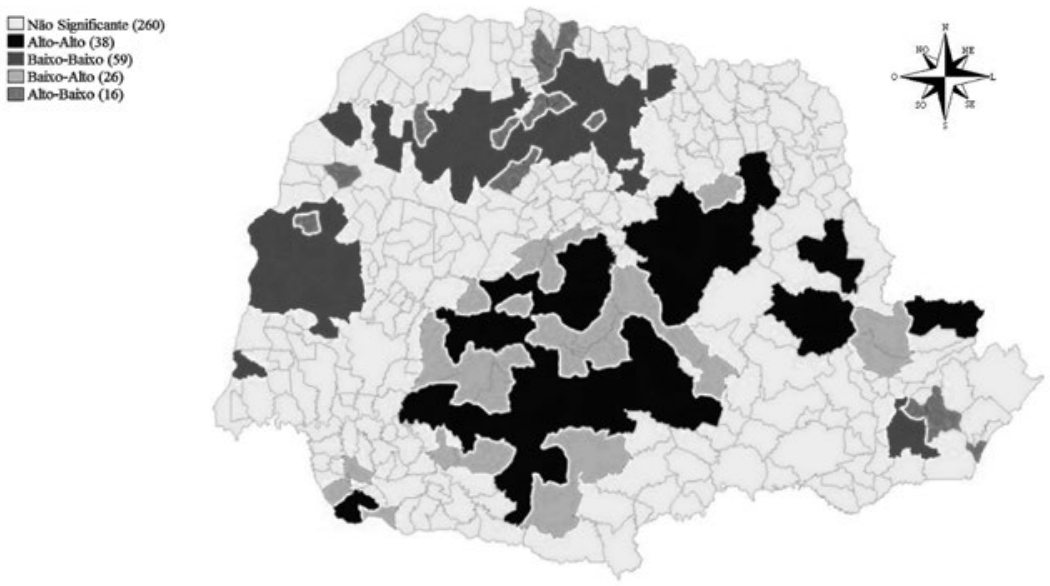

Fonte: elaborado pelos autores com base nos dados do Ipardes (2015) e MDS (2015).

lação espacial das duas variáveis, nota-se a predominância de dois clusters, baixo-alto e alto-baixo.

A partir da análise da mapa 2, no Centro Sul paranaense, predomina-se o padrão baixo-alto, isto é, nesse agrupamento de municípios, há uma baixa taxa de emprego na indústria de transformaçáo e uma alta taxa de proporção de famílias beneficiadas. Tendo em vista essa caracterização, em seguida será apresentado os munícipios que se destacaram-se e sua taxa para proporção de famílias beneficiadas, como também a taxa de emprego na indústria de transformação, respectivamente: Laranjal (43\% e 0.2\%), Goioxim ( $41 \%$ e $0.3 \%$ ), Mato Rico (39\% e $0.13 \%$ ), Rio Bonito do Iguaçu (38\% e $0.74 \%$ ), Marquinho (36\% e 0\%), Novas Tebas (35\% e $0.005 \%)$. Nota-se que esse padrão não é relevante apenas no Centro Sul, mas também em alguns municípios do Centro Oriental, como em Ortigueira e Curiúva, as quais apresentam alta taxa de proporção de famílias beneficiadas e uma baixa de emprego na Indústria de Transformação.

Já no Norte Central, Noroeste e uma pequena parte do Oeste, verifica-se a situação inversa. Há a predominância dos clusters Alto-Baixo, demonstrando que nesse agrupamento há uma maior taxa de Emprego na Indústria de Transformação e uma menor taxa de proporção de famílias beneficiadas pelo PBF. 


\section{Mapa 2}

Mapa de clusters bivariado para proporçáo de famílias beneficiadas pelo PBF e Taxa de Emprego na Indústria de Transformaçáo nos municípios paranaenses, 2010

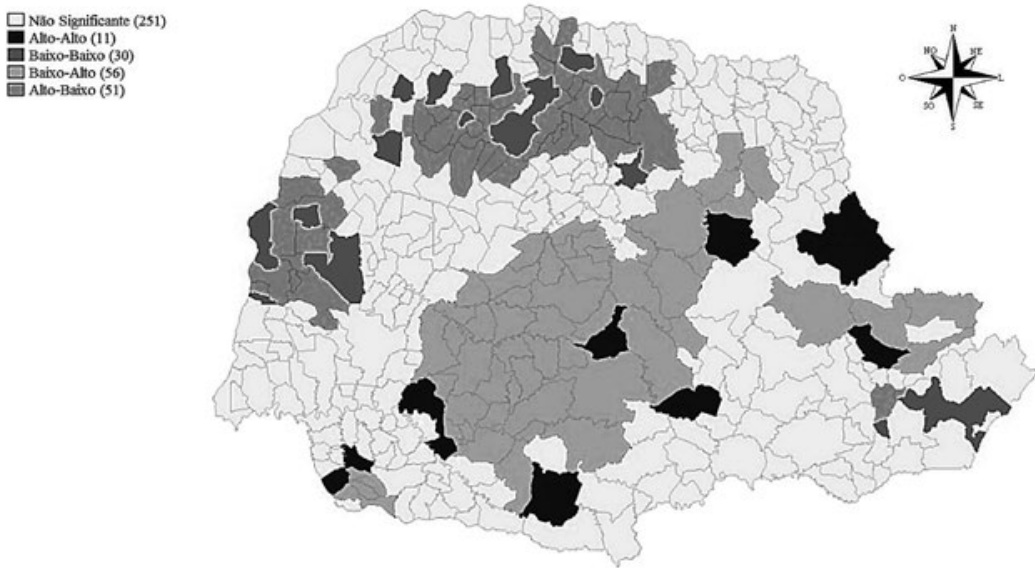

Fonte: elaborado pelos autores com base nos dados do Ipardes (2015) e MDS (2015).

Nessas regiōes observam-se munícipios relevantes para a compreensão da análise. Na região Norte Central, há São Tome, munícipio com a maior taxa de Emprego na Indústria de Transformação do Paraná (69.97\%) e uma baixa taxa de proporção de famílias beneficiadas (7.8\%), assim como Tapejara e São Carlos Ivaí na regiāo Noroeste, além de Toledo no Oeste do estado.

Na mapa 3, nota-se a predominância de clusters baixo-alto ealto-baixo, mas em uma menor intensidade do que o mapa anterior (mapa 2). Isso ocorreu porque o coeficiente de correlaçáo negativo entre a taxa de proporção de famílias beneficiadas e a taxa de emprego no Comércio está mais próximo de ser positivo do que a correlação entre a Indústria de Transformaçáo, como é apresentado no quadro 3.

Desse modo, o Centro Sul se destaca novamente no padrão baixo-alto, apresentando que nesse agrupamento de municípios há uma baixa taxa de emprego no Comércio e uma alta taxa para proporção de famílias beneficiadas. A seguir serão citados os munícipios que se destacaram e a taxa para proporção de famílias beneficiadas, como também a taxa desemprego no Comércio, respectivamente: Rio Bonito do Iguaçu (38.5\% e 3\%), Santa Maria do Oeste (36.3\% e 2.2\%), Palmital (32\% e 4.5\%), Candido de Abreu (31.3\% e 2.6\%,), Pinhão (27.1\% e 5.4\%). 


\section{Mapa 3 \\ Mapa de clusters bivariado para proporçáo de famílias beneficiadas pelo PBF e Taxa de Emprego no Comércio nos municípios paranaenses, 2010}

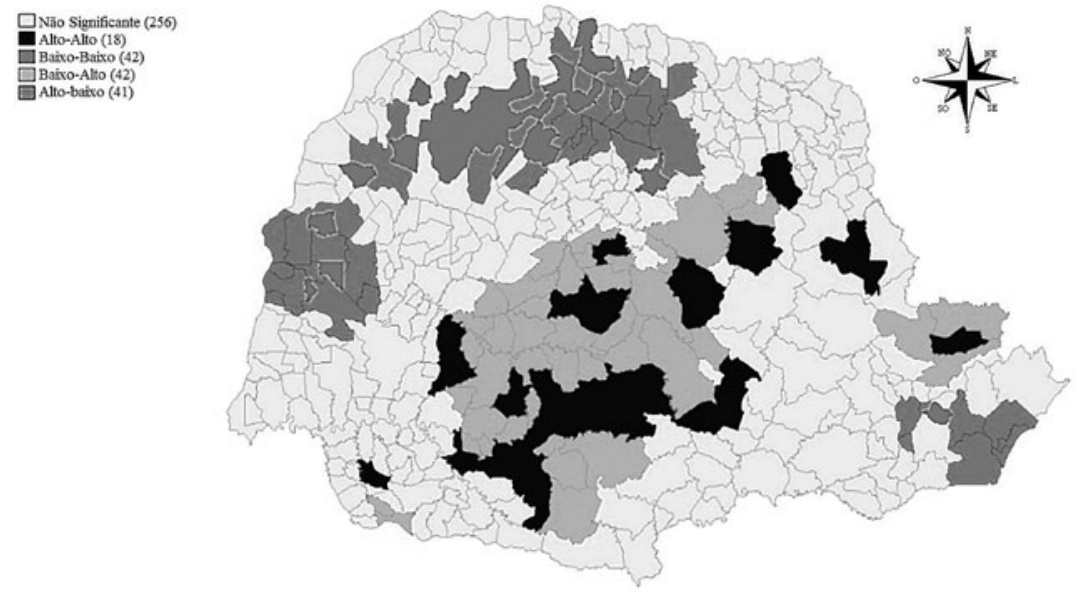

Fonte: elaborado pelos autores com base nos dados do Ipardes (2015) e MDS (2015).

Já no Norte Central, Noroeste e Oeste destaca-se cluster com padrão alto-baixo, caracterizando essas regióes como tendo uma alta taxa de emprego no comércio, porém uma baixa taxa de proporção de famílias beneficiadas. É o caso de Douradina, no Noroeste do estado, o qual tem a maior taxa de Emprego no Comércio (24.92\%) e sua taxa de proporção de famílias beneficiadas é de $9.5 \%$. Na região Norte Central, o município de Londrina possui uma taxa de emprego no Comércio de 15.3\%. Como também no Oeste do estado, o município de Marechal Cândido Rondon possui uma taxa de $14.1 \%$. Logo, todos esses municípios possuem baixa taxa de proporção de famílias beneficiadas.

De acordo com a mapa 4, o Centro Sul se destaca com um grande agrupamento de munícipios no padrão baixo-alto. Isso representa que nessa região existe uma baixa taxa de Emprego nos Serviços e alta taxa de proporção de famílias beneficiadas pelo PBF. Como é o caso de Nova Laranjeiras, o município possui a menor taxa de Emprego no setor em análise $(7.76 \%)$ e $32 \%$ é sua taxa para proporção de famílias beneficiadas. Outros municípios possuem taxas relevantes, como Pitanga, Prudentópolis, Roncador, Santa Maria do Oeste, Rio Bonito do Iguaçu, Marquinho, Nova Cantu, Nova Tebas, Ortigueira, Palmital e Turvo.

Mesmo o padrão alto-baixo não predominar, é relevante apresentar que a capital do estado, Curitiba, localizada na regiáo Metropolitana de 


\section{Mapa 4 \\ Mapa de clusters bivariado para proporçáo de famílias beneficiadas pelo PBF e Taxa de Emprego nos Serviços nos municípios paranaenses, 2010}

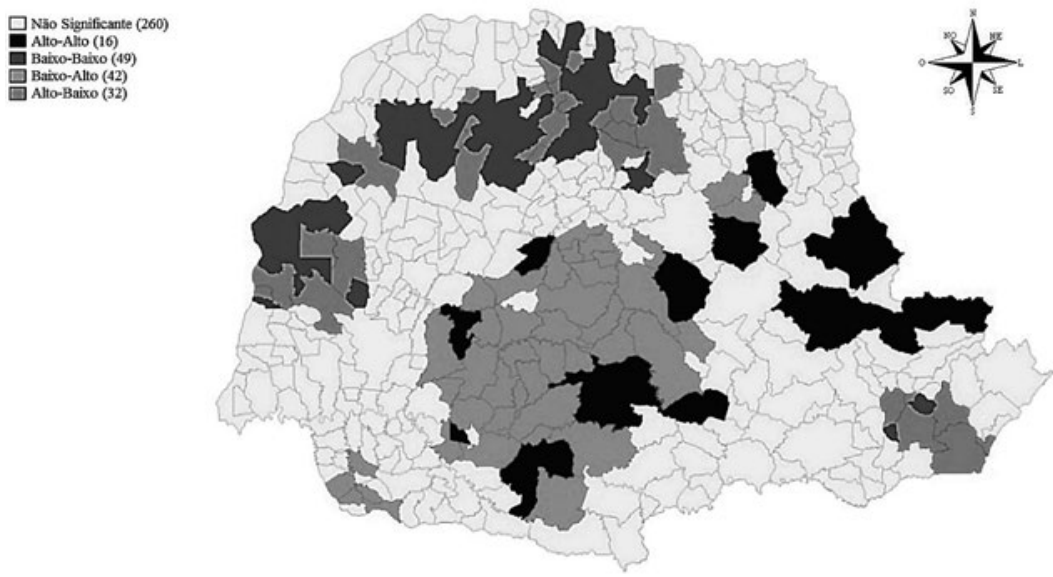

Fonte: elaborado pelos autores com base nos dados do Ipardes (2015) e MDS (2015).

Curitiba, mostrou-se com baixa proporção de famílias beneficiadas (6.7\%) e a maior taxa de Emprego nos Serviços (55.95\%).

A seguir, nos mapas de clusters será analisado o Emprego nos municípios paranaenses em 2010 que foi abordado até o momento, mas referindo-se ao Emprego por gênero, masculino e feminino.

Com base no mapa 5, observa-se que a região Centro Sul é caracterizada pelo cluster baixo-alto, demostrando que nesse agrupamento há uma menor taxa de Emprego Masculino e uma maior taxa para proporção de famílias beneficiadas pelo programa.

Assim, nessa mesorregião há alguns municípios com valores discrepantes em relação à média da taxa do Emprego Masculino (19.65\%). Como Goioxim, com uma taxa de $7.5 \%$ de Emprego Masculino e a sua taxa para proporção de famílias beneficiadas é de $41.4 \%$. Nova Laranjeiras, com uma taxa de $6.5 \%$ de Emprego Masculino e a sua taxa para proporção de Famílias Beneficiadas é de 32.7\%. Porém, esses municípios sáo pequenos, já os com uma maior populaçáo, suas taxas não são tão diferentes, como é o caso de Prudentópolis, Laranjeiras do Sul e Pinhão.

O mapa 6 aponta dois clusters predominantes, baixo-alto e alto-baixo, diferentemente do mapa 5, analisado anteriormente. Isso ocorreu pelo fato de que o coeficiente de correlação do Emprego Feminino está mais 


\section{Mapa 5 \\ Mapa de clusters bivariado para proporção de famílias beneficiadas pelo PBF e Taxa de Emprego Masculino nos municípios paranaenses, 2010}

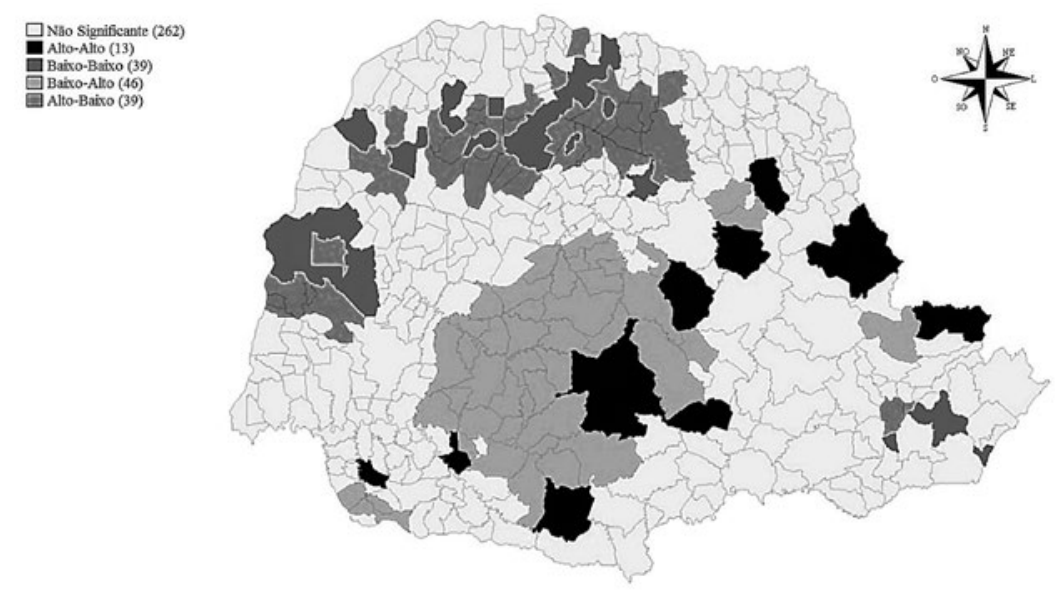

Fonte: elaborado pelos autores com base nos dados do Ipardes (2015) e MDS (2015).

distante de 0, comparando-se com o coeficiente do Emprego Masculino, observado no quadro 4.

À vista disso, no Centro Sul, se destaca um agrupamento baixo-alto, tendo assim uma menor taxa de Emprego Feminino e uma maior taxa para a proporçáo de famílias beneficiadas pelo PBF. Os municípios que se destacam e a taxa para proporção de famílias beneficiadas pelo PBF, como também a Taxa de Emprego Feminino serão apresentados a seguir, respectivamente: Campina do Simão (37.45\% e 8.16\%), Turvo (34.2\% e 11.87\%), Altamira do Paraná (32.9\% e 8.7\%), Pinhão (27.1\% e 8.09\%), Pitanga (23.64\% e $8.5 \%)$, Cantagalo (32.2\% e $10.9 \%)$.

Na mesorregiáo Norte Central, observa-se a situação inversa, como é o caso de Londrina, um grande município com uma Taxa de Emprego Feminino de $26.4 \%$ e a Taxa para a proporção de famílias beneficiadas pelo PBF é de $7.5 \%$.

Nota-se no mapa 7 que grande parte do Centro Sul predomina-se um agrupamento baixo-alto. À vista disso, observa-se que essa mesorregião possui alta taxa para proporçáo de famílias beneficiadas pelo PBF e uma baixa taxa do Saldo de Emprego Formal Total.

Portanto, os municípios que se destacam e a taxa para a proporção de famílias beneficiadas, como também a taxa do Saldo de Emprego Formal, serão apresentadas a seguir, respectivamente: Laranjal (43.5\% e 0\%), Rio 


\section{Mapa 6}

Mapa de clusters bivariado para proporção de famílias beneficiadas pelo PBF e Taxa de Emprego Feminino nos municípios

$$
\text { paranaenses, } 2010
$$

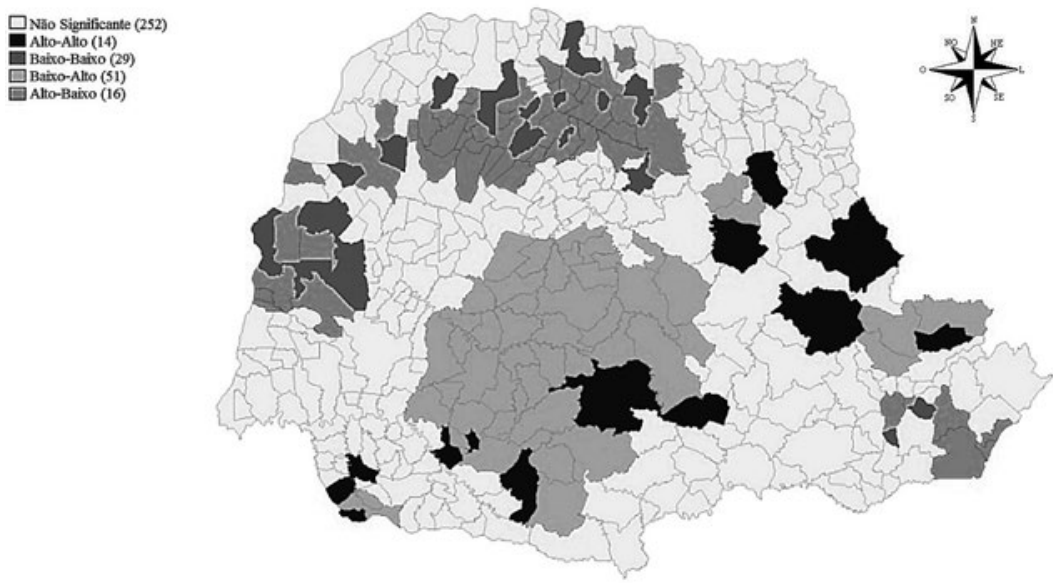

Fonte: elaborado pelos autores com base nos dados do Ipardes (2015) e MDS (2015).

\section{Mapa 7}

Mapa de clusters bivariado para proporçáo de famílias beneficiadas pelo PBF e Taxa do Saldo de Emprego Formal Total nos municípios paranaenses, 2010
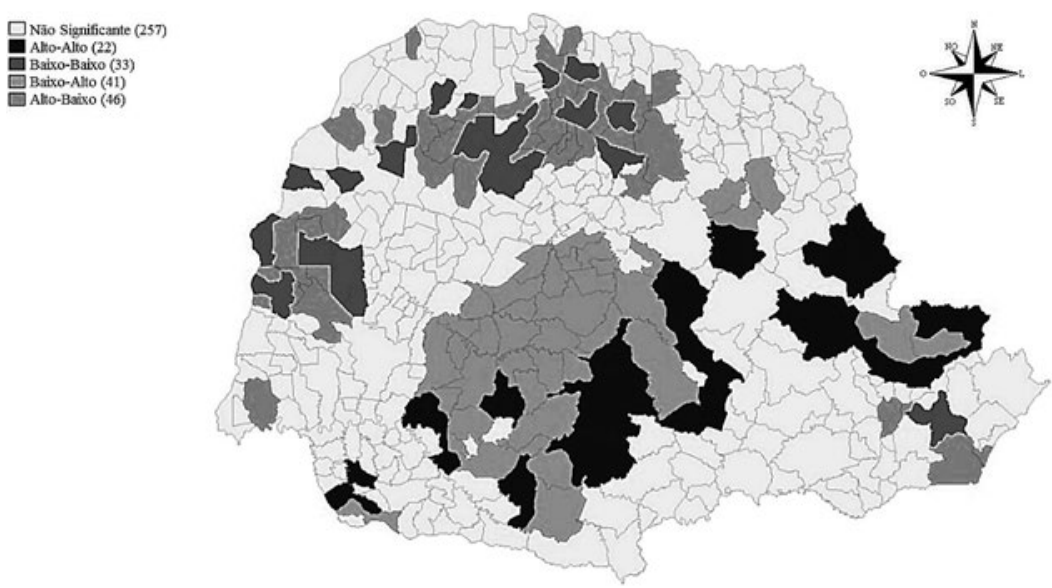

Fonte: elaborado pelos autores com base nos dados do Ipardes (2015) e MDS (2015). 
Bonito do Iguaçu (38.6\% e 1.1\%), Palmital (32\% e -0.6\%), Candido de Abreu (31.1\% e 0.7\%), Nova Laranjeiras (32.7\% e 05\%), Prudentópolis (23.4\% e $0.5 \%)$ e Nova América da Colina, município com a menor taxa do Saldo de Emprego Total no estado (-18.66) e com uma taxa para proporção de famílias beneficiadas pelo PBF de 19.5.

Os dois próximos mapas serão analisados a autocorrelação espacial com a Taxa do Saldo de Emprego Formal, mas referindo-se aos gêneros masculino e feminino.

De acordo com o mapa 8, nota-se a predominância do padrão alto-baixo nas Mesorregiōes Norte Central e Oeste paranaense. Logo, entende-se que nesses agrupamentos há uma alta taxa do Saldo de Emprego Formal Masculino e baixa Taxa para proporçáo de famílias beneficiadas pelo PBF.

Desse modo, no Norte Central verificam-se municípios com essa característica, como Arapongas, o qual possui uma Taxa do Saldo de Emprego Formal Masculino de 2\% e uma taxa de 6.17\% para proporção de famílias beneficiadas. $\mathrm{O}$ mesmo ocorre com outros municípios, tais como Sertanópolis, Cambé e Mandaguari. Já no Oeste, notam-se municípios como Assis Chateaubriand, Toledo, Terra Roxa e Pato Bragado.

Observa-se no mapa 9 que é evidente um agrupamento de municípios na mesorregião Centro Sul com um padrão baixo-alto. Demonstrando-se

\section{Mapa 8 \\ Mapa de clusters bivariado para proporção de famílias beneficiadas pelo PBF e Taxa do Saldo de Emprego Formal Masculino nos municípios paranaenses, 2010}

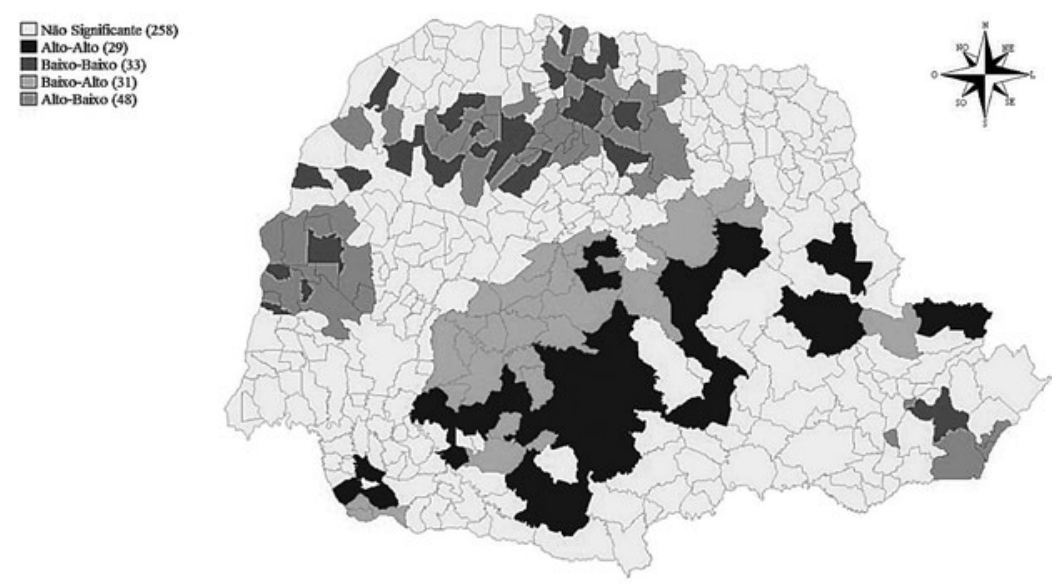

Fonte: elaborado pelos autores com base nos dados do Ipardes (2015) e MDS (2015). 
que nessa área há baixa taxa do Saldo de Emprego Formal Feminino e alta taxa para proporção de famílias beneficiadas pelo PBF.

Tal situação pode ser representada pelos municípios a seguir, como também suas respectivas taxas para proporção de famílias beneficiadas pelo PBF e de Emprego Formal Feminino: Guarapuava (19.5\% e 1.3\%), Pinhão (27.11\% e 0.74\%), Palmital (32\% e 16.5\%), Candói (26.45\% e $0.6 \%)$ e Jardim Alegre (24.64\% e $0.6 \%)$.

Ainda em relação ao mercado de trabalho, o mapa 10 mostra a associação espacial do PBF com a escolaridade no Paraná, destacando-se a mesorregião Centro Sul. Na qual concentra-se um padrão baixo-alto, isto é, nessa área há uma alta taxa para proporção de famílias beneficiadas e uma baixa taxa do Saldo de Emprego de Pessoas com Ensino Fundamental Completo.

Tal situação pode ser representada pelos municípios a seguir, como também suas respectivas taxas para proporção de famílias beneficiadas pelo PBF e de Emprego de Pessoas com Ensino Fundamental Completo: Pitanga (23.6\% e 3\%), Palmital (32\% e 1.63\%), Candói (26.45\% e 3.7\%), Nova Laranjeiras (32.7\% e 1.5\%), Laranjeiras do Sul (17.9\% e 3.6\%) e Campina do Simáo (37.5\% e 4.3\%).

\section{Mapa 9 \\ Mapa de clusters bivariado para proporçáo de famílias beneficiadas pelo PBF e Taxa do Saldo de Emprego Formal Feminino nos municípios paranaenses, 2010}

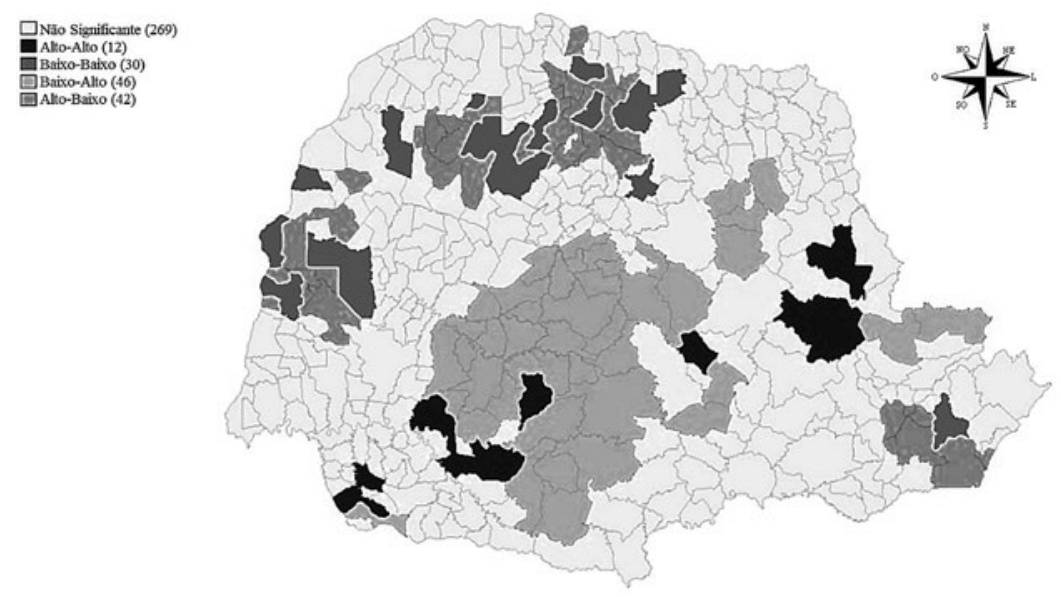

Fonte: elaborado pelos autores com base nos dados do Ipardes (2015) e MDS (2015). 


\section{Mapa 10 \\ Mapa de clusters bivariado para proporçáo de famílias beneficiadas pelo PBF e Taxa do Saldo de Emprego de Pessoas com Ensino Fundamental Completo nos municípios paranaenses, 2010}
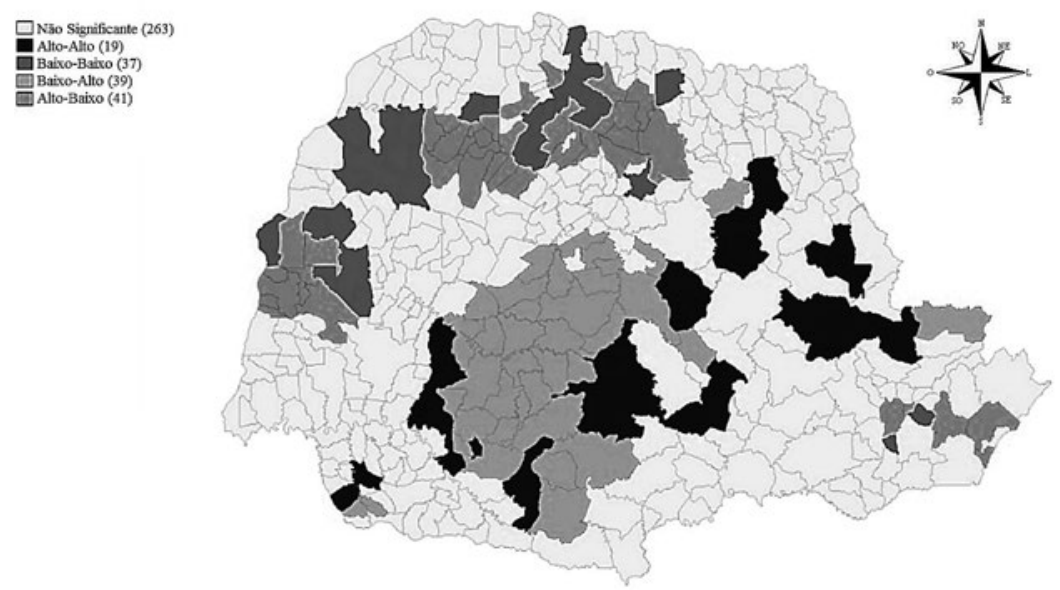

Fonte: elaborado pelos autores com base nos dados do Ipardes (2015) e MDS (2015).

Além disso, nota-se que no Oeste e Norte Central há clusters alto-baixo, porém acabam não sendo relevante para a presente análise, pois estes municípios estão circundados por áreas de um padrão baixo-baixo.

Interpretando-se o mapa 11, nota-se que várias mesorregióes se destacam, as quais são o Centro Sul (padrão baixo-alto), Norte Central e Noroeste (ambas concentrou-se o padrão alto baixo).

O Centro Sul apresenta municípios com baixa taxa de Emprego de Pessoas com Ensino Médio Completo. A seguir, observam-se algumas cidades como também suas respectivas taxas para proporção de famílias beneficiadas pelo PBF e de Emprego de Pessoas com Ensino Médio Completo: Santa Maria do Oeste (36.9\% e 4.8\%) e Goioxim (41.4\% e $2.1 \%)$. No Norte Central e Noroeste, ocorre a situação inversa, isto é, encontram-se áreas com alta taxa de Emprego de Pessoas com Ensino Médio Completo, logo, baixa taxa para proporção de famílias beneficiadas. Como Por exemplo, Londrina, Rolândia e Cidade Gaúcha.

Observa-se no mapa 12, que o Centro Sul novamente se destaca no padrão baixo alto, tendo assim uma alta taxa para proporção de famílias beneficiadas pelo PBF e uma baixa taxa de Emprego de Pessoas com Ensino Superior Completo.

Essa característica pode ser demonstrada por alguns municípios e suas respectivas taxas em estudo: Palmital (32\% e 1.8\%), Reserva $(25.7 \%$ e 


\section{Mapa 11}

Mapa de Clusters bivariado para proporçáo de famílias beneficiadas pelo PBF e Taxa do Saldo de Emprego de Pessoas com Ensino Médio Completo nos municípios paranaenses, 2010

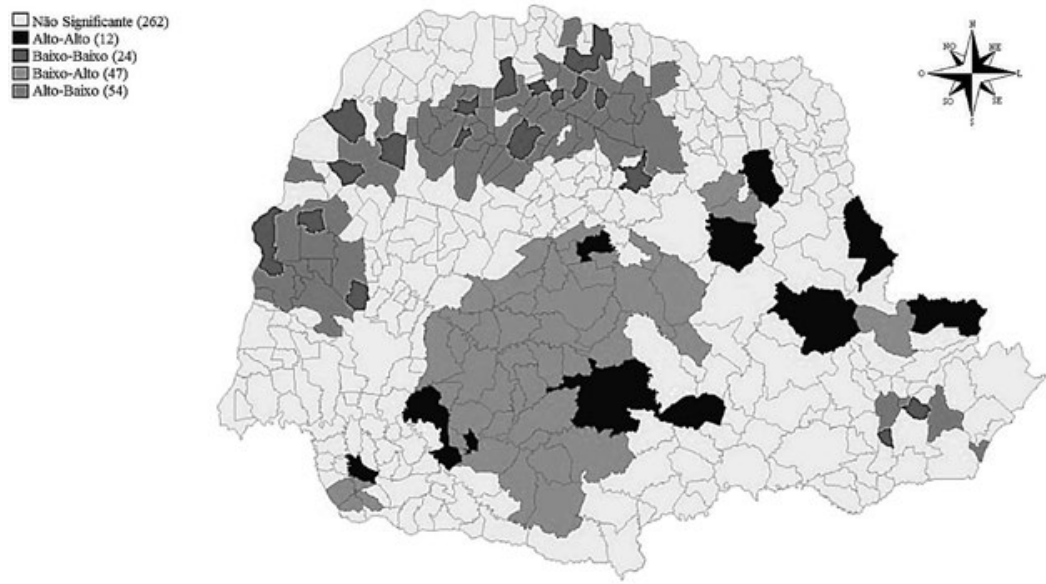

Fonte: elaborado pelos autores com base nos dados do Ipardes (2015) e MDS (2015).

\section{Mapa 12}

Mapa de clusters bivariado para proporçáo de famílias beneficiadas pelo PBF e Taxa do Saldo de Emprego de Pessoas com Ensino

Superior Completo nos municípios paranaenses, 2010

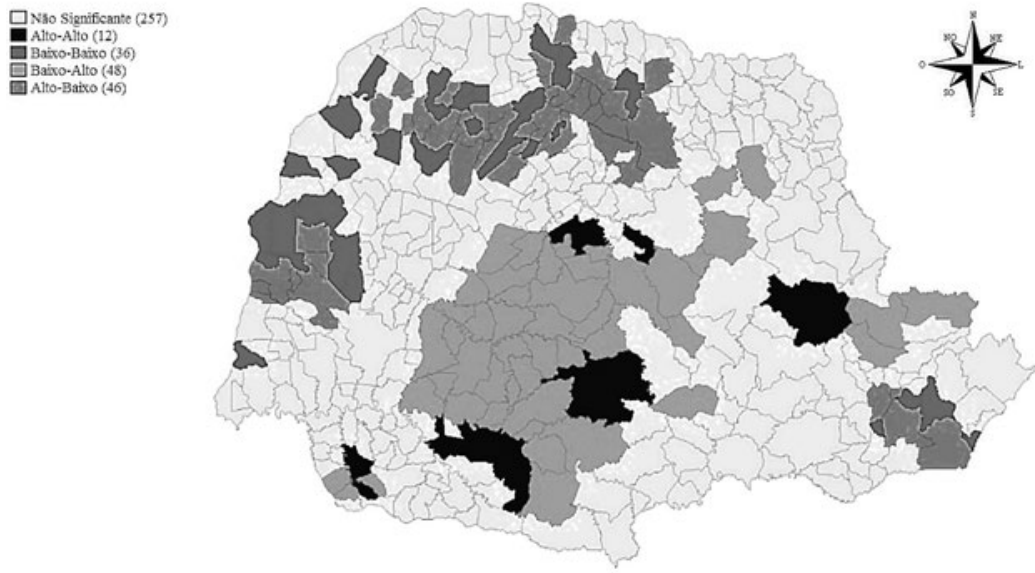

Fonte: elaborado pelos autores com base nos dados do Ipardes (2015) e MDS (2015). 
2.0\%), Cantagalo (32.2\% e 2.2\%), Iretama (29.9\% e 1.8\%) e Candido de Abreu (31.3\% e 2.6\%).

Além disso, observa-se no quadro 2 que o Coeficiente de Variação da Taxa do Emprego de Pessoas com ensino Superior Completo é a menor das três variáveis referentes a escolaridade. Logo, sabe-se que os valores da variável em estudo no Paraná não serão tão heterogêneos quanto na variável Taxa de Empregos de pessoas com Ensino Fundamental Completo (mapa 11).

A figura mapa 13 apresenta a predominância do padrão baixo-alto na mesorregião Centro Sul. À vista disso, interpreta-se que nesse agrupamento de municípios há uma maior taxa para proporção de famílias beneficiadas pelo PBF e um menor PIB per capita. Dentre os municípios que se destacam são: Campina do Simão, o qual tem uma maior taxa para proporção de famílias beneficiadas (37.5\%) e um PIB per capita de 553 . Também observa-se nesse agrupamento o município de Laranjal, com a maior taxa para proporção de famílias beneficiadas (43.53\%) em 2010, como mostra o quadro 3 da sessão 4.1, e um PIB per capita de 4.37.

\section{Mapa 13}

Mapa de clusters bivariado para proporçáo de famílias beneficiadas pelo PBF e PIB per capita nos municípios paranaenses, 2010

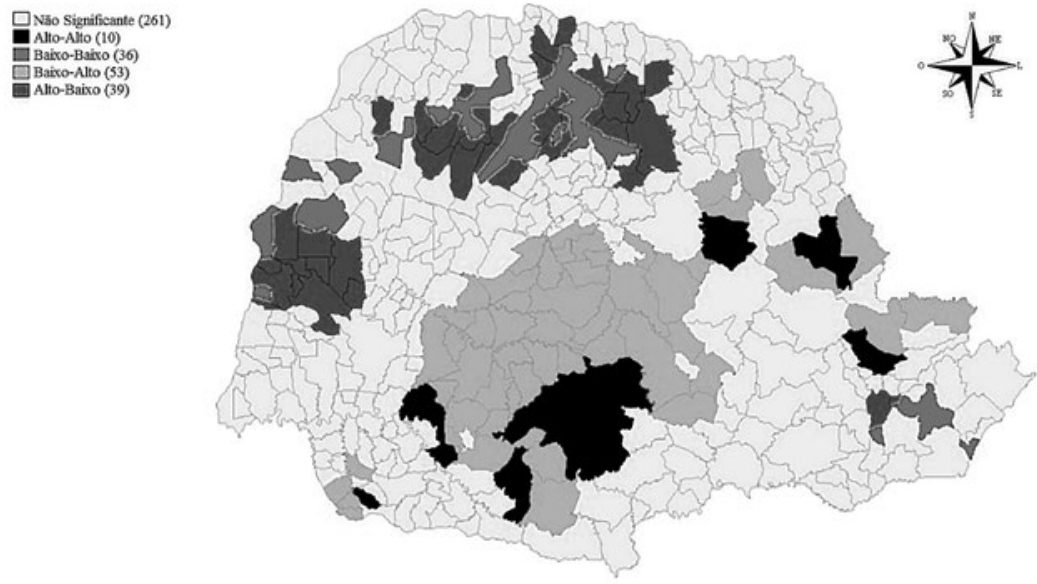

Fonte: elaborado pelos autores com base nos dados do Ipardes (2015) e MDS (2015). 


\section{Consideraçóes finais}

A pesquisa realizada buscou analisar se existe relação entre proporção de famílias beneficiárias do Programa Bolsa Família e o mercado de trabalho no Paraná em 2010. No que se refere ao mercado de trabalho, os resultados mostram que atividades ligadas ao setor urbano possuem forte relação linear com a proporção de famílias beneficiadas pelo PBF, mais especificamente a taxa de desemprego urbano, a qual foi a única variável que mostrou-se com uma correlação positiva. Além disso, a correlação com a Taxa de emprego na indústria de transformação, no comércio e nos serviços mostrou-se com uma relação linear inversa.

Já em relação ao gênero, como também na movimentação do mercado de trabalho, as pessoas do sexo feminino possuem um peso maior nos resultados, demonstrando que as mulheres têm uma maior relevância no programa em questáo. $\mathrm{O}$ mesmo ocorreu quando se correlacionou com os graus de escolaridade, mostrando que a correlaçáo com a taxa de pessoas com ensino médio completo possui uma associação linear mais forte, quando se compara com os outros graus de escolaridade.

Observa-se que o mercado de trabalho é acompanhado por relaçóes negativas quando se trata de emprego nos diferentes setores. Logo, a compreensão desse diagnóstico pode ser dada com a associação linear entre as variáveis, proporção de famílias beneficiadas pelo PBF e o PIB per capita municipal, que com um nível de significância de 5\%, o coeficiente foi negativo. Conclui-se que municípios que possuem PIB per capita elevado são acompanhados por baixa proporção de famílias beneficiadas pelo PBF. Desse modo, entende-se que municípios ou regióes que possuem PIB per capita alto pode haver maior geração de emprego e riquezas, havendo assim maiores oportunidades para a população de baixa renda.

Esclarecido o modo como as variáveis se comportaram, notou-se nos mapas de Clusters bivariado para proporção de famílias beneficiadas pelo $\mathrm{PBF}$ e as demais variáveis que o Centro Sul é evidenciado no padrão alto-baixo. Isso demonstra que a mesorregiāo possui um mercado de trabalho desfavorecido, tendo assim uma limitação para a geração de riquezas. Entretanto há maiores taxas para a proporção de famílias beneficiadas nos municípios.

Pela observação dos aspectos analisados pode-se rejeitar a hipótese nula, isto é, rejeita-se a hipótese de que não há interferências entre o $\mathrm{PBF}$ e o mercado de trabalho em 2010. Com base nisso, sugere-se a realizaçáo de pesquisas que possam ir além dos resultados alcançados aqui, como por exemplo, analisar o impacto da escolaridade sobre a proporção de famílias beneficiadas pelo programa Bolsa Família. 


\section{Referências bibliográficas}

Almeida, Eduardo Simões de (2004), Curso de econometria espacial aplicada, Escola Superior de Agricultura "Luiz de Queiroz" Universidade de São Paulo, Piracicaba, São Paulo, Brasil.

Anselin, Luc, Ibnu Syabri e Youngihn Kho (2006), "GeoDa: an introduction to Spatial Data Analysis", Geographical Analysis, 38 (1), Ohio State University, Columbus, Estados Unidos de America, pp. 5-22.

Ávila, Milene (2013), “O Bolsa Família e a pobreza no Brasil: 'detalhes' que fazem a diferença", tese doutorado, Universidade Estadual de Campinas, Instituto de Filosofia e Ciências Humanas, São Paulo, Brasil, <file://E:/2013/Downloads/AvilaMilenePeixoto_D\%20(1).pdf>, 15 de outubro de 2014.

Brauw, Alan, Daniel O. Gilligan, John Hoddinott e Shalini Roy (2013), "O Bolsa Família e a oferta de trabalho das famílias", International Food Policy Research Institute n. ${ }^{\circ} 239$, Centro Internacional de Políticas para o Crescimento Inclusivo (IPC-IG), Brasília, Brasil, <http://www.ipc-undp.org/pub/port/IPCOnePager239.pdf>, 18 de outubro de 2014.

Curralelo, Claudia Regina Baddini (2012), "O enfrentamento da pobreza como desafio para as políticas sociais no Brasil: uma análise a partir do Programa Bolsa Família”, tese doutorado, Universidade Estadual de Campinas, Instituto de Economia, São Paulo, Brasil, <file://E:/2013/Downloads/CurraleroClaudiaReginaBaddini_D\%20(1).pdf>, 20 de agosto de 2014.

Hoffmann, Rodolfo (2006), Estatística para economistas, Thomson, São Paulo, Brasil.

Ipardes (Instituto Paranaense de Desenvolvimento Econômico e Social) (2015), Base de Dados do Estado - BDEweb, Ipardes, Curitiba, Brasil, <http://www.ipardes.pr.gov.br/imp/index.php>, 28 de fevereiro de 2015.

Ipardes (Instituto Paranaense de Desenvolvimento Econômico e Social) (2004), Leituras Regionais: Mesorregião Geográfica Sudoes- 
te Paranaense, PR-Ipardes-BRDE, Curitiba, Brasil, <http:// www.ipardes.gov.br/biblioteca/docs/leituras_reg_meso_sudoeste.pdf $>, 12$ de outubro de 2014.

De Castro, Jorge Abrahão y Lúcia Modesto (2010), Bolsa família 2003-2010: avanços e desafios, Instituto de Pesquisa Econômica Aplicada, Brasília, Brasil, <http://www.ipea.gov.br/portal/ images/stories/PDFs/livros/livros/livro_bolsafamilia_vol2. pdf $>, 10$ de novembro de 2014.

Lazani, Rodrigo (2011), "Programas de transferência de renda: autonomia versus assistencialismo", dissertação mestrado, Universidade Estadual de Campinas, Instituto de Filosofia e Ciências Humanas, Campinas-São Paulo, Brasil, <http://repositorio. unicamp.br/handle/REPOSIP/278728>, 24 de setembro de 2014.

Licio, Elaine Cristina; Camile Sahb Mesquita e Claudia Regina Baddini Curralero (2011), "Desafios para a coordenação intergovernamental do Programa Bolsa Família”, RAE-revista de administração de empresas, 51 (5), Fundação Getúlio Vargas-São Paulo School of Business Administration, São Paulo, Brasil, pp. 458-470, < http://www.scielo.br/pdf/rae/v51n5/ a04v51n5.pdf>, 13 de outubro de 2014.

Marques, Rosa Maria, Áquilas Mendes, Marcel Guedes Leite e Ana Hutz (2007), “A Importância do Bolsa Família nos Municípios Brasileiros. Avaliação de Políticas e Programas do MDS Resultados", em Jeni Vaitsman e Rômulo Paes-Sousa (orgs.), Avaliação de Políticas e Programas do MDS - Resultados, Secretaria de Avaliação e Gestão da Informação Ministério do Desenvolvimento Social e Combate à Fome, Brasília, Brasil, $<$ http://docplayer.com.br/8232242-Avaliacao-de-politicas-e-programas-do-mds-resultados.html>, 26 de agosto de 2014.

MDS (Ministério do Desenvolvimento Social e Combate à Fome) (2015), "Data social: base de dados" MDS, Brasília, Brasil, $<$ http://aplicacoes.mds.gov.br/sagi-data/METRO/metro. php?p_id=4>, 8 de abril de 2015.

MDS (Ministério do Desenvolvimento Social e Combate à Fome) (2017), "Bolsa Família: benefícios" MDS, Brasilia, Brasil,: 
$<$ http://mds.gov.br/assuntos/bolsa-familia/o-que-e/beneficios/>, 9 de julho de 2017.

Oliveira, Ana Maria Hermeto Camilo, Mônica Viegas Andrade, Anne Caroline Costa Resende, Clarissa Guimarães Rodrigues, Laeticia Rodrigues de Souza e Rafael Perez Ribas (2007), "Primeiros resultados da análise da linha de base da pesquisa de avaliação de impacto do Programa Bolsa Família. Avaliação de políticas e programas do MDS Resultados", em Jeni Vaitsman e Rômulo Paes-Sousa (orgs.), Avaliação de Políticas e Programas do MDS - Resultados, Ministério do Desenvolvimento Social e Combate à Fome, Brasília, Brasil, pp. 19-65, $<$ http://docplayer.com.br/8232242-Avaliacao-de-politicas-e-programas-do-mds-resultados.html>, 16 de agosto de 2014.

Pinto, Renato César Martins (2012), "Impactos da política econômica no combate à pobreza no governo Lula (2003-2010)", Trabalho de Conclusão de Curso apresentado para obtenção do título de Bacharel em Ciências Econômicas, Instituto de Economia da Universidade Estadual de Campinas, Campinas, Brasil pp. 1-57, $<$ http://www.bibliotecadigital.unicamp.br/document/?code $=000904106 \&$ opt $=1>, 14$ de setembro de 2014 .

R Core Team (2015), "R: A language and environment for statistical computing", R Foundation for Statistical Computing, Vienna, Austria, < http://www.R-project.org/>, 28 de fevereiro de 2015.

Rocha, Sonia (2011), O Programa Bolsa Família: evolução e efeitos sobre a pobreza”, Economia e Sociedade, 20 (1), Instituto de Economia da Universidade Estadual de Campinas, Campinas, Brasil, pp. 113-139, <http://www.scielo.br/pdf/ecos/v20n1/v20n1a05>, 2 de setembro de 2014.

Soares, Sergei e Natália Sátyro (2009), “O programa bolsa família: desenho institucional, impactos e possibilidades futuras", texto para discussão n. ${ }^{\circ}$ 1424, Instituto de Pesquisa Econômica Aplicada, Brasília, Brasil, <http://repositorio.ipea.gov.br/bitstream/11058/2598/1/TD_1424.pdf>, 15 de outubro de 2014.

Suárez, Mireya y Marlene Libardoni (2007), "O Impacto do Programa Bolsa Família: mudanças e continuidades na condição social das mulheres. Avaliação de políticas e programas do MDS Resulta- 
dos”, em Jeni Vaitsman e Rômulo Paes-Sousa (orgs), Avaliação de Politicas e Programas do MDS - Resultados, Ministério do Desenvolvimento Social e Combate à Fome, Brasília, Brasil, <http:// gestaocompartilhada.pbh.gov.br/sites/gestaocompartilhada.pbh. gov.br/files/biblioteca/arquivos/avaliacao_de_politicas_e_programas_do_mds_-_resultados_-vol._2.pdf >, 16 de outubro de 2014 .

Recibido: 5 de julio de 2016. Aceptado: 14 de febrero de 2017. Corregido: 17 de abril de 2017.

Rayssa Vieira Kruger. Graduanda do curso de Economia da Universidade Federal da Fronteira Sul. Suas últimas publicaçóes destacam-se em co-autoria, "Macroeconomia Heterodoxa: um Estudo Sobre a Teoria Keynesiana e de seus sucessores (neokeynesianos e novos keynesianos) e a Política Econômica Brasileira no Período de 1994-2015”, Anais da Jornada de Iniciação Científica e Tecnológica, 6 (1), Universidade Federal da Fronteira Sul, Chapecó, Brasil, pp. 1-4 (2016); "As contribuiçóes de Amartya Sen e Robert Putnam para as Análises do Desenvolvimento Rural: consideraçóes sobre o Território da Cidadania Cantuquiriguaçu-PR", em $52^{\circ}$ Congresso da SOBER, Universidade Federal de Goiás, 27 a 30 de julho, Goiânia, Brasil (2014).

Paulo Alexandre Nunes. Possui graduação em Ciências Econômicas pela Universidade Estadual de Londrina, mestrado em Economia pela Universidade Estadual de Maringá. Atualmente é professor assistente da Universidade Federal da Fronteira Sul, atuando principalmente nos seguintes temas: arranjo produtivo local, Paraná, desenvolvimento econômico, armazenagem e construção civil. Entre suas últimas publicaçóes em co-autoria, destacam-se: "Estrutura produtiva do Território da Cantuquiriguaçu com abordagem insumo-produto para o ano de 2010", Gestão e Desenvolvimento em Revista, 1 (1), Universidade Estadual do Oeste do Paraná, Paraná, Brasil, pp. 116-132 (2015); "Desempenho setorial das microrregióes do norte central paranaense de 2000 a 2010", Perspectiva Econômica, 11 (1), Universidade do Vale do Rio dos Sinos Editoria de Periódicos Científicos, São Leopoldo, Brasil, pp. 64-80 (2015); "Estudo do impacto socioeconômico do crédito rural no território cantuquiriguaçu-pr", Gestão e Desenvolvimento em Revista, 1 (2), Universidade Estadual do Oeste do Paraná, Paraná, Brasil pp. 66-84 (2015). 
Deise Maria Bourscheidt. Possui graduação em Ciências Econômicas pela Universidade Federal de Santa Maria e mestrado em Economia pela Universidade Federal do Espírito Santo. Atualmente é professora assistente da Universidade Federal da Fronteira Sul. Tem experiência na área de Economia, com ênfase em Macroeconomia e Desenvolvimento Sustentável. Entre suas últimas publicações em co-autoria, destacan-se: "Multi-sectorial convergence in greenhouse gas emissions", Journal of Environmental Management, 196, Elsevier, Amsterdam, Pa\{ises Baixos, pp. $402-410$ (2017). 